\title{
Componentes antinutricionais e digestibilidade proteica em sementes de abóbora (Cucurbita maxima) submetidas a diferentes processamentos
}

\author{
Antinutritional components and protein digestibility in pumpkin seeds (Cucurbita maxima) \\ submitted to different processing methods
}

\author{
Luciana de Paula NAVES ${ }^{1 *}$, Angelita Duarte CORREA ${ }^{2}$, \\ Custódio Donizete dos SANTOS ${ }^{2}$, Celeste Maria Patto de ABREU²
}

\begin{abstract}
Resumo
Subprodutos vegetais têm sido utilizados na dieta com a finalidade de melhorar o estado nutricional de populações desnutridas. Entretanto, os antinutrientes presentes nesses alimentos podem acarretar efeitos indesejáveis. Portanto, os teores de polifenóis, cianeto, saponinas, inibidor de tripsina, atividade hemaglutinante e a porcentagem da digestibilidade proteica in vitro de sementes de abóbora cruas e tratadas termicamente foram investigados com o objetivo de selecionar o processamento que acarrete maior redução dos antinutrientes e maior digestibilidade proteica. Sementes da abóbora Cucurbita maxima foram, em quatro repetições, submetidas aos seguintes tratamentos: utilizadas na forma crua; cozidas em água em ebulição (AE) por três tempos: 5, 10 e 15 minutos; e cozidas no vapor por 10 minutos. Posteriormente foram liofilizadas, trituradas e armazenadas em temperatura ambiente até a realização das análises. Não houve diferença significativa, entre os tratamentos, quanto aos níveis de polifenóis. As sementes cruas apresentaram o maior teor de cianeto, o menor nível de inibidor de tripsina e a menor digestibilidade proteica. O cozimento em AE por 10 minutos acarretou o menor nível de saponinas e a maior digestibilidade proteica. Não foi detectada atividade hemaglutinante em nenhuma amostra. Conclui-se que o cozimento em AE por 10 minutos foi o que proporcionou melhores resultados.
\end{abstract}

Palavras-chave: Cucurbita maxima; semente de abóbora; processamento; antinutriente; digestibilidade proteica.

\begin{abstract}
Vegetable subproducts have been used in diets with the purpose of improving the nutritional quality of undernourished populations. However, the antinutrients present in those foods can cause adverse health effects. Therefore, the contents of polyphenols, cyanide, saponins, trypsin inhibitor, hemaglutinin activity, and the percentage of the in vitro protein digestibility of raw and thermally treated pumpkin seeds were investigated with the objective of selecting the processing that results in major antinutrient reduction and greater protein digestibility. Pumpkin seeds (Cucurbita maxima) were submitted to the following treatments, which were carried out in quadruplicate: used raw; boiled for 5, 10, and 15 minutes; and steamed for 10 minutes. Next, the seeds were freeze-dried, grinded, and stored at room temperature until the analyses were completed. There was no significant difference among the treatments as for the levels of polyphenols. The raw seeds showed the highest content of cyanide, smallest level of trypsin inhibitor, and smallest protein digestibility. The 10-minute boiling resulted in the lowest content of saponins and greatest protein digestibility. No Hemaglutinin activity was detected in the samples. It can be concluded that the 10-minute boiling was the treatment that produced better results.

Keywords: Cucurbita maxima; pumpkin seed; processing; antinutrient; protein digestibility.
\end{abstract}

\section{Introdução}

Infelizmente, a fome e a desnutrição ainda são causas de doenças e morte de pessoas, principalmente em países subdesenvolvidos e em desenvolvimento. Uma das medidas adotadas para melhorar o estado nutricional de populações desnutridas inclui a utilização de subprodutos vegetais, ou seja, baseia-se no aproveitamento de partes da planta não consumidas e, portanto, desperdiçadas. Dentre esses subprodutos estão incluídas as sementes de abóbora, as quais possuem, principalmente, teores elevados de proteína e óleo.

Entretanto, há questionamentos sobre as possíveis interferências negativas causadas pelos antinutrientes presentes nos alimentos. Tais compostos podem interferir na digestibilidade e absorção dos nutrientes ou serem tóxicos, dependendo da quantidade em que são consumidos.

Os polifenóis são, em alguns casos, em especial os taninos, considerados antinutrientes devido à propriedade que apresentam em formar complexos principalmente com proteínas, podendo diminuir a digestibilidade proteica.

O consumo de significativas doses de cianeto, advindas de alimentos ricos em glicosídeos cianogênicos e pobremente processados, pode resultar em intoxicações crônicas e agudas, causando anomalias tais como a doença de Konzo (YEN et al., 
1995). O cianeto também apresenta notável poder tóxico pelo fato de ser um potente inibidor da citocromo oxidase, o que resulta no bloqueio da cadeia de transporte de elétrons durante o processo de respiração celular.

As saponinas constituem uma classe ampla, apresentando diversas ações biológicas nos animais. Dentre os efeitos indesejáveis que podem causar, destacam-se as alterações na reprodução e no crescimento e a redução na absorção de nutrientes em função de modificações na permeabilidade de membranas celulares (FRANCIS et al., 2002).

As lectinas são glicoproteínas com propriedade de ligar-se especificamente a certos carboidratos. Podem acarretar efeitos degenerativos nas membranas celulares e inibir a ação de enzimas digestivas interferindo na absorção de nutrientes e no crescimento. Podem ainda, ser letais se consumidas em elevadas doses (PEREIRA et al., 2008).

A digestibilidade proteica é um parâmetro nutricional muito importante porque avalia o aproveitamento de uma fonte proteica, fornecendo, portanto, uma mensuração da susceptibilidade da proteína à proteólise. Pode ser influenciada pelo tratamento térmico, presença de polifenóis, inibidores de tripsina e lectinas, entre outros (CHEFTEL et al., 1993).

Embora estudos recentes defendam que o consumo de pequenas quantidades de alguns desses antinutrientes pode trazer benefícios ao organismo humano, as doses adequadas para promover tais benefícios ainda não foram estabelecidas. Portanto, é muito importante investigar e selecionar processamentos simples e eficazes na redução dos teores dos antinutrientes presentes nos alimentos.

Del-Vechio et al. (2005) determinaram os teores de alguns antinutrientes em sementes submetidas a três tratamentos, cruas, cozidas em água em ebulição e tostadas, das seguintes espécies de abóbora: Cucurbita maxima (CMA), Cucurbita moschata $(\mathrm{CMO})$ e o híbrido F1 $(\mathrm{CMA} \times \mathrm{CMO})$. Concluíram que a CMA apresentou os níveis mais baixos de cianeto e polifenóis e a maior digestibilidade proteica in vitro; e que, dentre os tratamentos usados, o cozimento em água em ebulição foi o mais eficiente em reduzir os níveis da maioria dos antinutrientes investigados, além de acarretar aumento da digestibilidade proteica.

A proposta deste trabalho foi dar continuidade à pesquisa iniciada por Del-Vechio et al. (2005) utilizando-se sementes da abóbora Cucurbita maxima submetidas a cinco tratamentos: sementes cruas; cozidas em água em ebulição por três tempos, 5, 10 e 15 minutos; e cozidas no vapor por 10 minutos, com o objetivo de avaliar a influência do tratamento aplicado e do tempo de cozimento sobre os níveis dos antinutrientes e digestibilidade proteica nas sementes pesquisadas.

\section{Material e métodos}

\subsection{Obtenção das abóboras e preparo das amostras}

As abóboras Cucurbita maxima, popularmente conhecidas por moranga, foram adquiridas no comércio varejista hortifrutigranjeiro do município de Lavras - MG e encaminhadas ao Laboratório de Bioquímica do Departamento de Química da
Universidade Federal de Lavras - MG, onde foram lavadas em água destilada, sanitizadas com hipoclorito de sódio $200 \mathrm{mg} . \mathrm{L}^{-1}$ em imersão por 10 minutos, cortadas em fatias e separadas nas porções: casca, polpa, fiapos e sementes. Em seguida, as sementes foram submetidas aos seguintes tratamentos, em quatro repetições cada: a) cruas (forma natural); b) cozidas em água em ebulição (AE), na proporção de 1:5 (massa das sementes em g/volume de água destilada em $\mathrm{mL}$ ) por 3 tempos: $5,10 \mathrm{e}$ 15 minutos; c) cozidas no vapor por 10 minutos.

As sementes cruas e submetidas aos diferentes tratamentos de cozimento foram congeladas em nitrogênio líquido, liofilizadas até massa constante e trituradas em moinho com peneira de 40 mesh. A farinha de sementes de abóbora (FSA) resultante dos diferentes tratamentos foi armazenada em frascos de vidro hermeticamente fechados à temperatura ambiente até posteriores análises.

\subsection{Análises químicas}

\section{Polifenóis}

Os polifenóis foram extraídos em condensador de refluxo com metanol a $50 \%$, por três vezes consecutivas, usando chapa aquecedora a $80{ }^{\circ} \mathrm{C}$. Os extratos obtidos foram reunidos, evaporados até o volume de $25 \mathrm{~mL}$ e submetidos à dosagem colorimétrica $(\lambda=760 \mathrm{~nm})$ com o uso do reagente de Folin-Denis (composto por tungstato de sódio, ácido fosfomolíbdico e ácido fosfórico). O ácido tânico foi usado como padrão (GOLDSTEIN; SWAIN, 1963).

\section{Cianeto}

A extração dos glicosídeos cianogênicos da FSA foi feita sob agitação horizontal por 15 minutos, em temperatura ambiente, utilizando-se solução de ácido clorídrico 0,1 mol.L ${ }^{-1}$. $\mathrm{O}$ extrato obtido teve o $\mathrm{pH}$ ajustado para 6,0 e foi centrifugado a $2000 \times$ g/15 minutos (IKEDIOBI et al., 1980 modificado por CORREAA et al., 2002). Ao sobrenadante recolhido foi acrescentada a enzima linamarase obtida de folhas de mandioca conforme metodologia descrita por Corrêa et al. (2002). Em seguida, a mistura foi encubada a $30{ }^{\circ} \mathrm{C}$ por 1 hora e, após esse período, a solução de ácido pícrico saturado/carbonato de sódio foi adicionada. Após repouso de 10 minutos, adicionou-se água à mistura e os tubos foram submetidos ao banho-maria em ebulição por 12 minutos, sendo o teor de cianeto medido colorimetricamente em $\lambda=530 \mathrm{~nm}$. O cianeto de potássio foi usado como padrão (WOOD, 1966).

\section{Saponinas}

As saponinas da FSA foram obtidas por extração com etanol $99 \%$, sob agitação horizontal por 1 hora, em temperatura ambiente. O extrato obtido foi centrifugado a $10000 \times \mathrm{g} / 10$ minutos e o sobrenadante foi recolhido. O nível de saponina foi determinado colorimetricamente $(\lambda=430 \mathrm{~nm})$ pela reação com o anisaldeído, em meio ácido, usando digitonina como padrão (BACCOU; LAMBERT; SAUVAIRE, 1977). 


\section{Inibidor de tripsina}

A FSA foi suspensa em solução de hidróxido de sódio 0,01 mol.L $\mathrm{L}^{-1}$ e agitada horizontalmente por 1 hora, em temperatura ambiente. Após centrifugação (3000 × g/10 minutos), uma alíquota do sobrenadante foi usada para o ensaio enzimático empregando-se a enzima tripsina e o substrato BApNA (benzoilDL-arginina-p-nitroanilida) para verificação da existência de inibidor da ação da tripsina sobre o BapNA na amostra pesquisada. A atividade do inibidor de tripsina foi expressa em unidades de tripsina inibida (UTI) (KAKADE et al., 1974).

\section{Atividade hemaglutinante}

A FSA foi suspensa em solução de cloreto de sódio 0,85 g. $100 \mathrm{~mL}^{-1}(\mathrm{pH}=7,4)$ e agitada por 3 horas, em temperatura ambiente. Em seguida, o extrato foi filtrado e a atividade hemaglutinante foi determinada utilizando-se placas de microtitulação, $100 \mu \mathrm{L}$ de suspensão de eritrócitos $2 \%$ (sangue humano $\mathrm{A}^{+}$) foram adicionados a $100 \mu \mathrm{L}$ do extrato da amostra fazendo-se uma série de diluições na base $2\left(2^{0}\right.$, $2^{1}, 2^{2}, 2^{3}$, etc.), seguida de repouso por 1 hora, em temperatura ambiente. Posteriormente, verificou-se, por meio de leitura visual, a presença ou não de aglutinação de células sanguíneas, sendo o resultado confirmado após 30 minutos. Paralelamente, utilizou-se uma testemunha, que consistiu apenas de suspensão de eritrócitos. Os resultados foram expressos pelo expoente, da base 2 , correspondente à última diluição em que foi observada aglutinação visível de eritrócitos (BARCA; OCHOA; VALENCIA, 1985).

\section{Digestibilidade proteica in vitro}

A FSA (com teor de nitrogênio conhecido) foi submetida à digestão pela enzima pepsina e posteriormente pela pancreatina em seus $\mathrm{pH}$ ótimos, sendo a digestão interrompida pela adição de ácido tricloroacético. Em seguida, fez-se a centrifugação $(10000 \times \mathrm{g} / 15$ minutos), dosando-se o teor de nitrogênio no sobrenadante. A caseína foi usada como padrão (AKESON; STAHMANN, 1964). O valor da digestibilidade da caseína obtido foi considerado como $100 \%$, e o valor da digestibilidade obtido para a FSA foi calculado em função do valor obtido para a caseína.

\section{Análises estatísticas}

Este experimento foi realizado em delineamento estatístico inteiramente casualizado, com cinco tratamentos e quatro repetições. Os dados foram submetidos à análise de variância e, quando significativa, o teste de Tukey foi usado para as comparações das médias entre os tratamentos, a $5 \%$ de probabilidade (GOMES, 1990). Para a realização das análises estatísticas, foi utilizado o software SISVAR 4.6.

\section{Resultados e discussão}

Os teores de antinutrientes e a digestibilidade proteica in vitro da FSA submetidas aos cinco tratamentos estão apresentados na Tabela 1. Não foram observadas diferenças significativas $(\mathrm{P}=5 \%)$, entre os tratamentos aplicados, quanto aos teores de polifenóis, enquanto que para cianeto, saponinas, inibidor de tripsina e percentual de digestibilidade proteica observaram-se diferenças com grau de significância ao nível de $\mathrm{P}=1 \%$.

O teor médio de polifenóis determinado na FSA deste trabalho foi de $0,22 \mathrm{~g} .100 \mathrm{~g}^{-1}$ de matéria seca - MS. Segundo Del-Vechio et al. (2005), o cozimento em AE por 10 minutos e tostagem das sementes da moranga também não acarretaram diferenças significativas nos níveis deste antinutriente. O teor médio de polifenóis descrito por tais pesquisadores é semelhante (0,21 g.100 g-1 MS) ao determinado nesta pesquisa.

A ingestão de compostos fenólicos por humanos é de aproximadamente $1 \mathrm{~g} \cdot \mathrm{dia}^{-1}$ (SCALBERT; JOHNSON; SALTMARSH, 2005), estimativa esta que pode variar de acordo com os hábitos alimentares de cada indivíduo (MANACH et al., 2004). Assim, níveis superiores a esse serão atingidos somente se o consumo da FSA for superior a 455 g.dia ${ }^{-1}$. Consumo este considerado relativamente alto, o que diminui o risco de que malefícios causados por altas doses de polifenóis sejam adquiridos com a utilização da FSA em dietas como fonte nutricional alternativa ou complementar.

Apesar de não ter sido observada diferença significativa, quanto ao nível de cianeto, entre as sementes cozidas em AE por 10 e 15 minutos, de um modo geral, o cozimento reduziu os teores desse antinutriente, o que está de acordo com vários estudos científicos que indicam que o cianeto livre,

Tabela 1. Teores médios de antinutrientes, em matéria seca, e digestibilidade proteica in vitro ${ }^{\star}$ da farinha de sementes de abóbora (Cucurbita maxima) submetidas a cinco tratamentos.

\begin{tabular}{|c|c|c|c|c|c|}
\hline Tratamentos & $\begin{array}{l}\text { Polifenóis } \\
\left.\text { (g.100 g }{ }^{-1}\right)\end{array}$ & $\begin{array}{c}\text { Cianeto } \\
\left(\mathrm{mg} .100 \mathrm{~g}^{-1}\right)\end{array}$ & $\begin{array}{l}\text { Saponinas } \\
\left(\mathrm{g} .100 \mathrm{~g}^{-1}\right)\end{array}$ & $\begin{array}{l}\text { Inibidor de tripsina } \\
\left(\text { UTI }^{\prime} \mathrm{mg}^{-1}\right)\end{array}$ & $\begin{array}{c}\text { Digestibilidade proteica } \\
\text { in vitro }(\%)^{* *}\end{array}$ \\
\hline Cruas & $0,21^{\mathrm{a}}$ & $6,42^{\mathrm{a}}$ & $0,35^{\mathrm{a}}$ & $4,21^{\mathrm{d}}$ & $45,84^{\mathrm{e}}$ \\
\hline Cozidas em $\mathrm{AE}^{\ddagger} / 5$ minutos & $0,21^{\mathrm{a}}$ & $4,32^{\mathrm{b}}$ & $0,34^{\mathrm{ab}}$ & $9,51^{\mathrm{a}}$ & $69,06^{\mathrm{b}}$ \\
\hline Cozidas em AE/10 minutos & $0,21^{\mathrm{a}}$ & $3,36^{c}$ & $0,24^{\mathrm{c}}$ & $8,41^{\mathrm{b}}$ & $72,48^{\mathrm{a}}$ \\
\hline Cozidas em AE/15 minutos & $0,24^{\mathrm{a}}$ & $3,73^{\mathrm{c}}$ & $0,31^{\mathrm{b}}$ & $5,97^{\mathrm{c}}$ & $50,74^{\mathrm{d}}$ \\
\hline Cozidas ao vapor/10 minutos & $0,22^{\mathrm{a}}$ & $4,19^{\mathrm{b}}$ & $0,31^{\mathrm{b}}$ & $8,48^{\mathrm{b}}$ & $61,64^{\mathrm{c}}$ \\
\hline $\mathrm{CV}(\%)$ & 6,60 & 3,79 & 3,86 & 4,92 & 1,52 \\
\hline
\end{tabular}

${ }^{*}$ Médias de 4 repetições seguidas da mesma letra não diferem entre si (Teste de Tukey p $\left.\leq 0,05\right) .{ }^{\ddagger}$ AE: água sob ebulição. 'UTI: unidades de tripsina inibida. ${ }^{*}$ Valores corrigidos para caseína considerada $100 \%$ digerível. 
resultante da ação enzimática, é perdido durante o cozimento (DEL-VECHIO et al., 2005; NGUDI; KUO; LAMBEIN, 2003). A enzima responsável pela degradação do substrato glicosídeo cianogênico é hidrolítica e, desta forma, necessita da presença da água para atuar (CORRÊA et al., 2002). Portanto, as sementes cozidas em AE por 10 e 15 minutos apresentaram os menores níveis de cianeto, provavelmente, porque a enzima teve mais tempo para atuar no substrato. Dentre os processamentos usados por Del-Vechio et al. (2005), o cozimento em AE por 10 minutos também acarretou a maior perda de cianeto nas sementes da moranga. O teor de cianeto determinado nas sementes cruas nesta pesquisa $\left(6,42 \mathrm{mg} .100 \mathrm{~g}^{-1} \mathrm{MS}\right)$ é semelhante ao relatado por Del-Vechio et al. (7,00 mg. $100 \mathrm{~g}^{-1}$ MS) (2005). Em ambos os trabalhos, o maior teor de cianeto foi observado nas sementes cruas.

A dose letal de cianeto oscila entre 0,5 e 3,5 mg. $\mathrm{kg}^{-1}$ de peso corpóreo (WOGAN; MARLETTA, 1993). Portanto, para um indivíduo de $70 \mathrm{~kg}$, seria considerado seguro um consumo máximo de aproximadamente $545 \mathrm{~g}$ da FSA. Consequentemente, é provável que a utilização da FSA como suplemento alimentar não seja suficiente para ultrapassar o limite diário recomendado. Porém é necessário mencionar a possibilidade de toxicidade crônica atribuída à ingestão de doses menores de cianeto durante um prolongado período de consumo.

A redução dos níveis de saponinas na FSA foi significativa apenas nas sementes cozidas em AE por 10 minutos (0,24 g.100 g $\left.{ }^{-1} \mathrm{MS}\right)$, não sendo observada diferença, nos teores desse antinutriente, entre as sementes cozidas em AE por 15 minutos e cozidas no vapor por 10 minutos (0,31 g. $\left.100 \mathrm{~g}^{-1} \mathrm{MS}\right)$. Em estudos feitos com farinha de soja, Tarade et al. (2006) observaram que o aumento do tempo de cozimento acarretou maior redução nos teores destas substâncias, entretanto essa redução foi muito sutil. Os teores de saponinas nas sementes de soja variam significativamente $\left(0,07\right.$ a 5,1 g.100 $\left.\mathrm{g}^{-1} \mathrm{MS}\right)$ de acordo com a variedade, modo de cultivo e maturidade (SHIRAIWA; HARADA; OKUBO, 1991). Desta forma, os níveis de saponinas presentes na FSA da presente pesquisa estão na faixa de variação descrita para os grãos de soja.

A FSA crua apresentou o menor nível de inibidor de tripsina (4,21 UTI.mg $\left.{ }^{-1} \mathrm{MS}\right)$, resultado esse contrário ao esperado, devido ao comportamento termolábel da maioria dos inibidores de tripsina. Esse resultado está em desacordo com o descrito por Del-Vechio et al. (2005), os quais reportaram maiores níveis de inibidores de tripsina nas sementes cruas do que naquelas submetidas ao cozimento em AE por 10 minutos $(6,24 \mathrm{e}$ 1,39 UTI.mg ${ }^{-1}$ MS, respectivamente). Todavia, observou-se que houve redução nos teores deste antinutriente na FSA deste trabalho à medida que se aumentou o tempo de cozimento em $\mathrm{AE}$, variando-se os níveis de 9,51 a 5,97 UTI.mg-1 MS. Além disso, observou-se que os diferentes tipos de cozimento por 10 minutos (em água em ebulição e no vapor) não acarretaram diferença significativa nos níveis de inibidores de tripsina.

Não foi detectada atividade hemaglutinante na FSA, o que representa um bom resultado, pois a aglutinação de células sanguíneas diminui a eficiência do sistema de transporte de oxigênio, entre outros fatores. Contudo, isto não descarta a possibilidade das sementes serem tóxicas quando consumidas em grandes quantidades. Del-Vechio et al. (2005) detectaram atividade hemaglutinante nas sementes cruas e cozidas em AE por 10 minutos nas diluições $2^{2}$ e $2^{1}$, respectivamente, entretanto o sangue humano utilizado por eles foi do tipo $\mathrm{B}^{+}$, enquanto que nesta pesquisa usou-se sangue humano do tipo $\mathrm{A}^{+}$. Isso indica que as lectinas presentes nas sementes da espécie Cucurbita maxima não aglutinam eritrócitos humanos de forma indiscriminada, já que mostraram certa especificidade para aglutinar células do sangue humano tipo $\mathrm{B}^{+}$e nenhuma especificidade com as células do sangue humano do tipo $\mathrm{A}^{+}$. As células sanguíneas presentes nos sangues humanos de tipo A e B apresentam diferentes carboidratos em sua superfície (FUDENBERG et al., 1980). Como as lectinas são glicoproteínas que se ligam a certos carboidratos de forma específica (SHARON; LIS, 2004), é provável que essa seja a principal explicação para a diferença observada, quando comparados os resultados da atividade hemaglutinante nesta pesquisa com os relatados por Del-Vechio et al. (2005). Outras possíveis explicações para esta diferença podem ser devido ao tempo de armazenamento das abóboras, época de colheita, maturidade das sementes, entre outros.

As sementes cruas apresentaram a menor digestibilidade proteica $(45,84 \%)$, enquanto as cozidas em AE por 10 minutos apresentaram a maior $(72,48 \%)$. Houve, portanto, um incremento de até $58,11 \%$. Como o tratamento térmico não alterou os níveis de polifenóis e os teores de inibidor de tripsina apresentaram-se baixos, parece não ter ocorrido relação entre estes compostos e a digestibilidade proteica. Portanto, essa melhoria na digestibilidade é provavelmente resultante de mudanças na conformação tridimensional das proteínas (desnaturação proteica) ocasionada pelo cozimento das sementes em AE por 10 minutos, o que parece ter favorecido a ação das enzimas proteolíticas. Os valores da digestibilidade proteica determinados nas sementes cruas e cozidas em AE por 10 minutos nesta pesquisa foram, respectivamente, em torno de $30 \%$ menor e $8 \%$ maior, quando confrontados com aqueles referidos por Del-Vechio et al. (2005). Essas diferenças podem ser explicadas em função de vários fatores: o tempo de armazenamento das abóboras, a época de colheita, a maturidade das sementes, entre outros.

\section{Conclusões}

Os níveis de polifenóis não foram influenciados pelo tipo nem pelo tempo de cozimento das sementes da abóbora Cucurbita maxima, entretanto, observou-se redução dos teores de cianeto e saponinas quando submetidas ao cozimento. $\mathrm{O}$ aumento do tempo de cozimento das sementes em água em ebulição reduziu a ação de inibidores de tripsina, todavia o menor valor para este parâmetro foi observado nas sementes cruas, contrariando os padrões citados na literatura. O cozimento das sementes em água em ebulição por 10 minutos reportou uma maior redução tanto nos conteúdos de cianeto quanto de saponinas, além de acarretar a maior digestibilidade proteica dentre os tratamentos aplicados.

Conclui-se, portanto, que o cozimento das sementes em água em ebulição por 10 minutos foi o que acarretou melhores resultados. 


\section{Agradecimento}

À FAPEMIG (Fundação de Amparo à Pesquisa do Estado de Minas Gerais) pela concessão do auxílio à pesquisa e da bolsa de iniciação científica (Processo n ${ }^{\circ}$ CAG-1142/03).

\section{Referências bibliográficas}

AKESON, W. R.; STAHMANN, M. A. A pepsin pancreatin digest index of protein quality evaluation. Journal of Nutrition, v. 83, n. 3, p. 257-261, 1964.

BACCOU, J. C.; LAMBERT, F.; SAUVAIRE, Y. Spectrophotometric method for the determination of total steroidal sapogenin. Analyst, v. 102 , n. 1215 , p. $458-465,1977$.

BARCA, A. M. C. de la; OCHOA, J. L.; VALENCIA, M. E. Effect of the extraction of a hemaglutinin on the nutritive value of Amaranthus leocarpus seeds. Journal of Food Science, v. 50, n. 6, p. 1700-1702, 1985.

CHEFTEL, J. C. et al. Química de los alimentos. 2 ed. Zaragoza: Acribia, 1993. p. 275-414.

CORRÊA, A. D. et al. Farinha de folhas de mandioca I: efeito da secagem das folhas sobre a atividade da linamarase. Ciência e Agrotecnologia, v. 26, n. 2, p. 368-374, 2002.

DEL-VECHIO, G. et al. Efeito do tratamento térmico em sementes de abóboras (Cucurbita spp.) sobre os níveis de fatores antinutricionais e/ou tóxicos. Ciência e Agrotecnologia, v. 29, n. 2, p. 369-376, 2005.

FRANCIS, G. et al. The biological action of saponins in animal systems: a review. British Journal of Nutrition, v. 88, n. 6, p. 587-605, 2002.

FUDENBERG, H. H. et al. Imunologia básica e clínica. 2 ed. Rio de Janeiro: Guanabara Koogan, 1980.

GOLDSTEIN, J. L.; SWAIN, T. Changes in tannins in ripening fruits. Phytochemistry, v. 2, n. 4, p. 371-383, 1963.

GOMES, F. P. Curso de estatística experimental. 13 ed. São Paulo: Nobel, 1990. 468 p.

IKEDIOBI, C. O.; ONYIA, G. O. C.; ELUWAH, C. E. A rapid and inexpensive enzymatic assay for total cyanide in cassava (Manihot esculenta Crantz) and cassava products. Agricultural and Biological Chemistry, v. 44, n. 12, p. 2803-2809, 1980.

KAKADE, M. L. et al. Determination of trypsin inhibitor activity of soy product: a collaborative analysis of an improved procedure. Cereal Chemistry, v. 51, n. 3, p. 376-382, 1974.

MANACH, C. et al. Polyphenols: food sources and bioavailability. The American Journal of Clinical Nutrition, v. 79, n. 5, p. 727-747, 2004.

NGUDI, D. D.; KUO, Y. H.; LAMBEIN, F. Cassava cyanogens and free amino acids in raw and cooked leaves. Food and Chemical Toxicology, v. 41, n. 8, p. 1193-1197, 2003.

PEREIRA, C. A. et al. Hemaglutinina de folhas de mandioca (Manihot esculenta Crantz): purificação parcial e toxicidade. Ciência e Agrotecnologia, v. 32, n. 3, p. 900-907, 2008.

SCALBERT, A.; JOHNSON, I. T.; SALTMARSH, M. Polyphenols: antioxidants and beyond. The American Journal of Clinical Nutrition, v. 81, n. 1, p. 215S-217S, 2005.

SHARON, N.; LIS, H. History of lectins: from hemaglutinins to biological recognition molecules. Glycobiology, v. 14, n. 11, p. 53R-62R, 2004

SHIRAIWA, M.; HARADA, K.; OKUBO, K. Composition and content of saponins in soybean seed according to variety, cultivation year and maturity. Agricultural and Biological Chemistry, v. 55, n. 2, p. 323-331, 1991.

TARADE, K. M. et al. Kinetics of degradation of saponins in soybean flour (Glycine max.) during food processing. Journal of Food Engineering, v. 76, n. 3, p. 440-445, 2006.

WOGAN, G. N.; MARLETTA, M. A. Componentes perjudiciales o potencialmente perjudiciales de los alimentos. In: FENNEMA, O. R. Química de los alimentos. 2 ed. Zaragoza: Acribia, 1993. p. $775-811$.

WOOD, T. The isolation, properties, and enzymic breakdown of linamarin from cassava. Journal of the Science of Food and Agriculture, v. 17, n. 2, p. 85-90, 1966.

YEN, D. et al. The clinical experience of acute cyanide poisoning. The American Journal of Emergency Medicine, v. 13, n. 5, p. 524-528, 1995. 